\title{
The Role of Small Bettors in Price Formation in Betting Exchanges
}

\author{
Isabel Abinzano \\ Universidad Publica de Navarra and INARBE \\ Luis Muga (Contact Author) \\ Universidad Publica de Navarra and INARBE \\ Phone: 34948166079 \\ Email: luis.muga@unavarra.es \\ Campus Arrosadia s/n; 31006 Pamplona, Navarra, (Spain) \\ Rafael Santamaria \\ Universidad Publica de Navarra and INARBE
}

\begin{abstract}
The presence of small bettors in betting exchanges generates mispricing, which can lead to exploitation by informed traders or result in permanent price deviations. This paper shows that mispricing from this source is also dependent upon variables of established relevance such as tournament round, the level of attention to the event, the volume of the betting, and bet type, further confirming these findings by means of cumulative accuracy profile (CAP) curves. It also offers evidence of the relevant role played by the type of device used to place the bet, whereby higher mispricing is observed in live bets placed via a mobile device, which appears to be associated with impulsive betting. This last finding could have practical implications for the regulation of the use of mobile devices to access gambling platforms.
\end{abstract}

Keywords: Betting Exchanges, Market Efficiency, Noise Bettors, Behavioral Finance

JEL Codes: L83, G02, G12, G14

Acknowledgements: We thank carcaj.com, Raúl Ibañez and Ruben Mangas for their help and support with the data. Financial support from the Spanish Ministry of Economy and Competitiveness, Project ECO2016-77631-R and Fundación Caja Navarra FUNCAN-07445 are gratefully acknowledged. 


\section{1.- Introduction}

Small-traders' effects on asset pricing in financial markets is the subject of recurring debate in the literature. Small investors have generally been classed as uninformed or noisy traders. In terms of market efficiency, Fama (1970) claims that pricing is unaffected by the presence of this type of traders, stating that trades should not be correlated and claiming that, in the event of their being so, arbitrageurs would be able to exploit any price deviations and prices would revert to equilibrium. Addressing the issue from the "Behavioral Finance" perspective, however, De Long et al. (1990) present a theoretical model of possible pricing effects in the presence of a high percentage of uninformed investors leading to so-called "noise trader risk" and thence to short-term price deviations that cannot be eliminated by arbitrageurs. Finally, based on a micro-structural analysis, Glosten and Milgrom (1985) claim that the presence of noisy traders encourages informed trading, whereby the private information of sophisticated traders is incorporated into prices.

While in all the above cases, small traders are considered unable to access or correctly process available market information, their impact on pricing varies with the theoretical model selected. Thus, mispricing due to small traders is a matter of particular concern in markets where they have a significant presence.

One context in which small traders have a major presence is sport betting. Although an important strand of the literature focuses on the efficiency of sport betting markets (Vaughan-Williams, 1999; Kuypers, 2000; Lyócsa and Výros, 2018), much less attention has been paid to the impact of small bettors on the odds, and the empirical evidence in this respect is mixed. Thus, Brown and Yang (2019) find higher odds-setting efficiency in larger markets where there is a greater share of uniformed bettors, while Abinzano et al. (2017) show that inefficiencies are greater in markets with lower average bet size and consequently a smaller share of informed bettors. Testing the impact of the presence of small bettors is no easy task, however, because most studies have no direct means of measuring their impact on trading. The literature has used proxies such as match-type (Lahvička, 2014) and day-of-the-week (Flepp et al., 2014).

It might be useful, therefore, to determine whether small traders' decisions, and thereby odds setting, are influenced by the type of market organization. Market microstructure is a key factor in determining how bets are matched and settled, but market organization has 
not remained stable through time. The development of the Internet and mobile platforms, in particular, have influenced both betting marketing strategies and betting market microstructure, as already noted by Brindley (1999). In bookmakers' markets, these factors have created increased competition, leading bookmakers to sharpen their odds. This effect has been considered both in theoretical (Franck et al., 2011) and empirical work (Del Corral and Prieto-Rodriguez, 2010; Lyócsa and Fedorko, 2016). Another of the effects of the development of Internet trading platforms has been to create an alternative form of market organization, now widely known as betting exchanges, where there are no bookmakers as such. Would-be bettors simply have to send an order to the platform, where it is executed if there is another to match it in price and volume, or held in order of price priority until matched. The consequences on price-setting of this alternative form of market organization were described in Jones et al. (2004).

The available empirical evidence indicates that the prices offered by betting exchanges are more efficient than those offered by bookmakers in overall terms, although the degree of efficiency depends on market liquidity (Franck et al., 2010). Little is known, however, about the specific effect on small punters in price formation, since the available evidence is drawn from comparative results across different types of markets, which are very likely to have different bettors' mix.

Furthermore, and as already stated, the development of Internet platforms has also influenced the way sports betting is marketed. The internet and mobile platforms have brought touchpoints (through which firms reach the consumer) closer to the points-ofsale (at which the purchase, or in this case the bet, takes place), as reported by Hing et al. (2018b), who find that this has resulted in more effective wagering inducements leading to impulsive betting in online betting channels.

Literature on purchasing habits is consistent with this idea. It has shown that the means used to make the purchase (or, in this case, the device to place the bet) has a great impact on a wide range of variables, including the consumer's information retention and processing mechanism, shopping experience (see Fuentes and Svingstedt, 2017) or marketing experience (Shankar and Balasubramanian, 2009). It should be stressed, however, that the relevance of all these factors can vary across product categories and points-of-sale (Sohn, 2017). 
Against this background, this paper aims to analyse the impact of the presence of small bettors on pricing in a relatively liquid betting exchange, in order to determine whether the odds really are against them. A further objective is to examine whether the matched odds are affected by potential behavioural biases due to factors such as the degree of media attention to the match, which round of the tournament is in progress, whether or not the bet is on the favourite, and the type of bet (whether it is a back bet or a lay bet, i.e., for or against a player). Special attention will also be paid to the device used to place the bet, since this can proxy for impulsive versus non-impulsive betting. The data used to address these objectives are drawn from a unique database containing all bets on tennis matches in the 2017 Australian Open placed by the clients of the Spanish betting company, Carcaj.com, through a major betting exchange, matchbook.com.

The rest of the paper is structured as follows. Section two describes the main organizational forms for betting markets. Section three offers a review of the literature on potential pricing variables in these markets. The database is given in Section four, the results in Section five and the main conclusions are presented and discussed in Section six.

\section{2.- Online betting market organization alternatives}

The two main alternatives for the organization of online betting markets, bookmakers and betting exchanges, reflect the standard for asset markets, that is, price-driven and orderdriven, double auction markets, respectively.

In bookmakers' markets, it is the betting firm which offers bid and ask prices, which are then entered in the order book. Betting firms may update prices in accordance with available market information and their derived expectations. On seeing the odds, bettors of whatever type may proceed to make an effective transaction, that is, to place a bet. Such orders are bets on a certain result occurring. As an example, let us take Match Betting on a tennis match where the odds for player A versus player B are 1.819 / 2.17; this means that, successfully backing player A yields 0.819 monetary units per unit staked, while the return on successfully backing player B to win is 1.17 per unit staked. Once sent, the order has to be accepted by the bookmaker. Contrary to the case in a pricedriven financial market, in a bookmaker market, the odds volumes are not displayed and there are no other bookmakers (market makers, i.e., broker-dealers) or specialists 
(designated market makers, i.e., dealers) to bring liquidity to the market. In other words, each bookmaker acts independently, although, as already noted, the development of online betting has forced firms to adjust their prices to remain competitive as predicted by Brindley (1999). Obviously, there cannot be a null bid-ask spread because some degree of spread is required for bookmakers to hedge their risks, particularly when dealing with an informed bettor.

Betting exchanges, on the other hand, are similar to so-called order-driven markets (Flepp, Nüesch and Franck, 2017). Here, it is the bettors' orders that make up the order book. In this case, the range of order prices is unlimited (although rarely shown on any platform beyond the first 3 levels). Since the orders are submitted by bettors, the market records not only the price but also the volume available (or parked) at that price. Thus, it is easy to deduce that, in this case, the bid-ask spread is not set by a dealer; it is rather the difference between the minimum acceptable rates of return per unit staked. By way of illustration, Figure 1 shows the odds listed by the Carcaj betting exchange for the 2017 Australian Open tennis final between Rafael Nadal and Roger Federer. As can be seen, the odds offered for Nadal winning the match were 1.819 (for a total volume of $€ 2,661$ at the first level of the order book) while the odds against it were 1.855 (for a total volume of $€ 100$ at the first level of the order book). Given that there were only two possible outcomes, that is, a win by Nadal or a win by Federer, laying Nadal should be the same as backing Federer. The formula for converting lay odds to back odds is written as follows:

$$
O_{B}=1+\frac{1}{o_{L}-1}
$$

In the above example, odds of 1.855 against Nadal winning would be equivalent to odds of 2.169 for Federer winning. In this market, therefore, a back bet on Federer to win (2.17) would be preferable to a lay bet on Nadal to lose (2.169).

The fact that there are two complementary markets, the market on the favourite and the market on the longshot, provides an opportunity for arbitrage and enables the transfer of information between the two (see Abinzano et al., 2017 and 2019). Although it also allows to observe a degree of bias in bettors' choices between "Back" or "Lay" bets, as reported by Brown and Yang (2018). 
Apart from market organization, the device used to access the market can also have relevance, especially if it is mobile device. In fact, in the mobile shopping context, smart phones in particular are changing the way in which consumers gather information and purchase goods (Grob, 2015 a and b), permitting new modes of social shopping, and enabling customers to share shopping experiences, all of which amounts to major changes for retailers (Fuentes and Svingstedt, 2017).

\section{3.- Literature Review}

As already stated, the main objective of this paper is to assess the impact of small bettors on pricing in betting exchanges. A specific aim is to test for mispricing in bets placed by small bettors and determine whether pricing errors increase in conditions under which traders are more likely to succumb to behavioural biases. In this respect, the literature on financial markets has reported a higher degree of behavioural biases among small than among institutional investors (Kumar, 2009; James and Karceski, 2006) and a higher disposition effect among retail investors than among fund managers (Frazzini, 2006). In betting markets, therefore, we might reasonably expect the behavioural biases to have, on average, a negative impact on the winnings of small bettors.

The empirical literature has shown that in betting markets, just as in financial markets, traders may succumb to behavioural biases. One of the most commonly-studied phenomena in betting-markets is the so-called Favourite-Longshot Bias (FLB). Basically, this is the result that higher winnings are to be made from betting on favourites than from betting on longshots. There are various explanations as to its origin, such as the impact on the odds from uninformed bettors equally distributing the probabilities of the different outcomes (Hurley and McDonough, 1995), the effect of bookmakers protecting themselves against better-informed traders (Kock and Shing, 2008; Lahvička, 2014; Rossi, 2011), or traders being affected by various types of cognitive bias (Gandhi and Serrano-Padial, 2015; Makropoulou and Markellos, 2011). Thus, in our betting exchange context we should find a positive link between betting in the longshot market and the mispricing which afflicts small bettors.

The literature has also shown that there is a series of variables in tennis betting markets, which can approximate concepts such as trader over-confidence or the media coverage of a given event. These variables have to do with the type of tournament, the round in the 
tournament or the characteristics of the players in a given match. Lahvička (2014), for example, finds that the type of tournament, the tournament round of the match, and the ranking of the players all have an impact on the level of FLB in bookmakers' tennis betting markets. Abinzano et al. (2016) provide further evidence for tennis betting exchanges. We ought therefore to find higher levels of mispricing in events with higher media coverage or those that are likely to generate overconfidence in bettors.

Generally, it can be assumed that matches in later rounds will attract more media attention and therefore greater betting volume (Abinzano et al. 2019). However, due precisely to the knock-out structure of the tournament, matches in later rounds are more likely to involve two players with similar skill levels (Del Corral and Prieto-Rodriguez, 2010 or Lyócsa and Fedorko, 2016), making the outcome harder to predict and increasing the magnitude of mispricing.

Brown and Yang (2018) show that bettors are not always able to discern the best price when about to place a bet in tennis betting exchanges, given that there are two complementary markets each offering a different way of betting on the same outcome: one can either back player A to win or lay player B to lose. This phenomenon may have more impact on the small bettors who provide the focus of this study, and whose payout may differ according to whether they place a back bet or a lay bet. As previously shown, back odds are directly interpretable. However to calculate bettor earnings, lay odds must be transformed by using expression (1). For this reason, we expect small unsophisticated bettors to make higher valuation errors when using lay odds.

One of the variables attracting most attention in the literature on betting markets is the betting volume, either in terms of total volume or in terms of average bet size, in a given market. Both are identified by Abinzano et al. (2019) as determining factors for explaining mispricing in tennis betting exchanges. Thus, higher total betting volume is associated with greater mispricing; while larger average bet size is associated with lower mispricing, where average bet size is a proxy for bettor sophistication. However, given that the majority of the sample for this study consists of small, unsophisticated bettors, bet size has no obvious interpretation. In a sample with these characteristics, bet size could be proxying for issues that have little to do with the degree of bettor sophistication. These authors also show that models including betting volume variables together with proxies for factors such as the above-mentioned media coverage or bettors' 
overconfidence could be affected by multicollinearity problems. Thus, the inclusion of both types of variable requires a degree of caution.

Finally, the literature on shopping habits has stressed the influence of the device used to make the purchase on factors such as the customer's capacity to store and process information and rating of the shopping experience (Fuentes and Svingstedt, 2017). It matters whether the chosen device is a computer or a mobile phone, because it will affect the way in which consumers gather information and do their shopping (Grob, 2015 a and b); the mobile phone has enabled new social shopping modes and shared shopping experiences, all with important implications for retailers (Fuentes and Svingstedt, 2017).

In the specific case of sports betting, the temptation to indulge in impulsive gambling may be greater when betting on a mobile device or using a betting site, where placing a bet is so quick and simple (Hing et al., 2018b). Furthermore, modern mobile phone technology facilitates a personalized, interactive gambling experience (James et al., 2017) and may be more effective in inducing in-play impulsive betting.

In as far as sports betting can be viewed as another form of asset consumption, where the social factor can play a major role, especially for participants in recreational betting groups during the lead-up to the event or while it is taking place it may reflect findings from the above-cited generic literature on shopping habits. Thus, Janhuba and Mikulka (2019) find evidence of the link between the choice of contact channel (telephone versus the Internet) and the success of bets placed in bookmakers' markets in the Czech Republic. In the case in hand, we can make a distinction between bets placed through a mobile app and those placed on the website. In theory, information gathering and processing should be more impulsive with bets placed through the mobile app, and the level of mispricing therefore greater.

Another phenomenon is mobile app betting advertising on the media, to encourage betting as an extra thrill during live sports broadcasts or, even, in social venues such as pubs (Parke et al., 2014).

On the one hand, Brown and Yang (2019) show, further, that when it comes to foretelling the final outcome of a given event, in-play bets have greater predictive power than preevent bets. It may be the case, however, that small bettors are slower to process a larger volume of information; whether or not this is case will determine whether we find evidence consistent with that of Brown and Yang (2019). Hing et al. (2018a), on the other 
hand, show that impulsive bettors are more likely to place in-play bets, while those who prefer to plan their bets tend to place them bets before play commences and also to have more betting accounts. Hing et al. (2018b) note, further, that impulsive betting has the characteristics of uninformed, unplanned decision-making, especially where young gamblers are involved. This literature would predict greater mispricing in live betting odds.

In summary, given the above literature, we might find the level of mispricing affecting small bettors to be influenced by variables such as the amount of attention to the event, tournament round, potential overconfidence in bettors, whether or not the bet is on the favourite, whether it is a back bet or a lay bet, whether or not it is an in-play bet, the choice of device used to place the bet, or the betting volume.

\section{4.- Database}

The data for this study were provided by www.carcaj.es ${ }^{1}$, a Spanish betting company, which supplied us with data for all bets through their platform on men's tennis matches in the 2017 Australian Open. This provided us with a study sample of 774 bets, 21 of which had to be removed due to cancellation prior to the match ending. This left a final sample of 753 individual bets on singles matches.

The said betting company operates as a betting exchange, which makes it very similar in functioning to an order-driven financial market (Abinzano et al., 2017). To ensure a sufficient level of liquidity, the betting company joined the www.matchbook.com platform, which is one of the world's largest betting exchanges. The bets that make up the sample have two basic characteristics. One is that the bettors are Spanish; the other is that they are small-scale, unsophisticated bettors, as will be illustrated later in this section.

The information given by the database enabled the construction of the following variables: $O D D S$ is the quote for the bet (its inverse is implied probability); RES is the dummy variable which tells us whether the bet is a winner or a loser; VOL stands for the amount staked ${ }^{2}$; TIME is a dummy variable which takes a value of 1 if the bet entered the

\footnotetext{
1 The data for this study were supplied to Carcaj.es by their technology provider, Xanadu Consultancy (Matchbook.com) and made available to the authors for research purposes. Unfortunately, www.carcaj.es ceased its activity on June 1, 2017.

${ }^{2}$ To facilitate comparison, the stakes on all lay bets were converted to the equivalent for back.
} 
market as a limited order; $F A V$ is a dummy variable that takes a value of 1 for bets placed in the favourite market; $L I V E$ is a dummy variable for "in play" bets; $L A Y$ is a dummy variable for lay bets (that is, bets against) in a given market; $A P P$ is a variable that takes a value of 1 if the bet was placed from a mobile app and 0 otherwise. Further variables used to proxy for media coverage of the event include $B I G 4$, which takes the value 1 if the match involves one of the four top media figures (Rafael Nadal, Roger Federer, Novak Djokovic or Andy Murray); TOP5, which takes the value 1 if the match involves one of the 5 players highest-seeded at the start of the tournament (Andy Murray, Novak Djokovic, Kei Nishikori; Stan Wawrinka or Milos Raonic); $Q F$, which takes the value 1 if it is a quarter-, semi- or final match, and $S P A$, a dummy variable which takes the value 1 for bets placed on matches where at least one of the players is Spanish.

One way to approximate betting mispricing, consistent with a proposal by Abinzano et al. $(2016,2019)$, is by means of the following expression:

$$
A b R I P_{t}=\left(R E S_{t}-I P_{t}\right)
$$

where $\mathrm{AbRip}_{t}$ is the bet mispricing t; $R E S_{t}$ is a binary variable that takes the value $1 \mathrm{for}$ a winning bet and 0 for a losing bet; and $I P_{t}$ is the probability implied by the odds for the bet. The implied probability is derived from the inverse of the odds (1/Odds).

Given that returns obtained by small bettors are expected to obtain negative returns, as already stated, the above variable is multiplied by -1 to obtain the final mispricing value, which is the main study variable in this paper and captures the degree of mispricing by small bettors within the market

$M I S_{t}=-A b R I P_{t}$

Table 1 lists all the matches for which bets were matched, indicating in each case the round involved, whether the bet was pre-event (PE) or in-play (IP), and whether it was for (a Back bet) or against (a Lay bet). While there is an almost even distribution between in-play and pre-event bets, the vast majority, on both favourites and longshots, are back bets $(95.38 \%$ and $84.90 \%$, respectively). Finally, it can be seen that late-round matches attract more betting attention; $9.67 \%$ of the bets on favourites and $12.42 \%$ of those on longshots involve the final match.

The descriptive statistics for the above-mentioned variables are reported in Table 2. It is worth noting that the sample is very largely made up of small bettors patronizing a 
Spanish betting company, and thus highly suited to the proposed objectives of this study. For example, $39.6 \%$ of the bets involve matches where at least one of the players was Spanish. The average bet size is $€ 113.81$, although it is perhaps more important to note that the median betting volume is $€ 20^{3}$. This illustrates that the vast majority of those betting through Carcaj.es are small bettors, and thus adequately satisfy the sample requirements for this study. It is also worth noting that over $90 \%$ of the bets are back bets and that $75 \%$ take the form of market orders, that is, there is no delay between the bet being placed and being matched against an order already on the order book. With respect to the event-attention proxies, $53.9 \%$ of the bets were on matches involving one of the big four players, $39.6 \%$ on quarter-, semi- or final matches, and $31.9 \%$ on matches involving one of the 5 highest-seeded players at the start of the tournament. $51.7 \%$ of the bets were placed in-play.

As already stated, previous literature has revealed a relationship between live betting and the type of device used to place the bet (Hing et al., 2018a). Thus, we should expect to find that most mobile app betting is live betting, such that $21.15 \%$ of pre-match bets are through a mobile app, versus $32.05 \%$ of live bets.

\section{5.- Results}

The first thing to note is that the variable $M I \mathrm{~S}_{t}$ has a positive average of 0.022 (Table 2) However, the $\mathrm{t}$ statistic for the variable indicates it is not significantly different from zero. In other words, bettors using this company to bet on this tournament show non-significant losses on average, which is unsurprising for small, unsophisticated traders operating in a liquid market. That is, this result shows that in general terms the matchbook.com market is efficient but that the small bettors, mostly unsophisticated back bettors, who access matchbook.com through carcaj.es, get a negative return on average. Our hypotheses make us expect that the more likely the bettors exhibit behavioural biases the greater the negative impact on their performance.

\footnotetext{
${ }^{3}$ Various studies have found considerably higher average bet size in Grand Slam tennis matches. For example, from a betting database covering Wimbledon Tennis Tournaments from 2008 to 2013, Brown and Yang (2018) report an average bet size of $£ 860$ for back orders and $£ 929$ for lay orders.
} 


\section{1.- Univariate analysis}

Given the potential impact of above-mentioned variables on pricing efficiency in this type of market, both stake sizes and pricing errors were subjected to univariate analysis (results shown in Table 3). It can be seen from Panel A that significantly higher stakes are placed on early-round matches (€164 versus $€ 36)$, matches not involving Spanish players (€158 versus $€ 45)$, matches involving favourites (€170 versus $€ 27)$ and on bets placed through the Web rather than on a mobile app (€137 versus $€ 57)$.

Panel B shows that the mispricing generated by bettors of Carcaj.es increases for highattention matches and those more likely to generate behavioural biases; specifically, this means matches involving big four players, with a mispricing difference of 0.102 and laterround matches, with a mispricing difference of 0.168 . However, this last variable (QF) might also be capturing difficulty of valuation due to these matches involving players of similar quality. The level of pricing error is higher for in-play bets, where the coefficient for the mispricing proxy shows a difference of 0.084. All these differences were significant according to the t-statistic. Significant differences in the form of higher mispricing are also found in bets placed on a mobile app (0.214) and lay bets (0.199). Finally, no significant differences in mispricing appear, however, between matches involving one of the top 5 in the ranking, a Spanish player, or a favourite and those involving any other player, or between market orders and limit orders.

As already stated, these results are consistent with previous empirical evidence showing higher mispricing in later rounds, and in matches involving high ranked players (Abinzano et al. 2016). Meanwhile, other variables show significant differences with respect to mispricing due to the presence of small bettors. One is the pre-event/in-play variable, such that mispricing increases in association with bets placed with the match already underway, thus lending support to the theory that small bettors are slow to process new information or bet more impulsively, versus that which says the outcome becomes easier to predict as match end approaches (Brown and Yang, 2019). Another is the variable for mobile app betting, in that the use of this software option is associated with higher mispricing, existing studies having associated impulsive betting with the use of these technological platforms (James et al., 2017); and a third is the variable for lay bets, thus linking these also to higher mispricing This last finding is consistent with the evidence reported in Brown and Yang (2018) where it is shown that bettors are unable to select the best prices among those offered by betting exchanges for tennis matches. 


\section{2.- Analysis of the predictive power of the small bettor}

Another way of approaching the issue analysed in the previous subsection is to study the predictive power of the odds selected by small bettors, where the expected association would be between more accurate prediction and lower mispricing.

In the context of business failure risk prediction, Sobehart et al. (2001) develop a series of measures evaluating the predictive power of bankruptcy probability measures including Cumulative Accuracy Profile (CAP) curves and Accuracy Ratios (AR). CAP curves, also known as "power curves", are useful in providing a visual evaluation of the predictive power of various time series models. However, because it is sometimes difficult to discriminate between two measures based solely on these graphs, it is recommended that the analysis be strengthened by including Accuracy Ratios (AR), which compresses the CAP curve data into a statistic, as in various studies such as Cantor and Mann (2003), Kealhofer (2003) or Gharghori et al. (2006). Brown and Yang (2019) use similar measures, such as ROC curves, in the context of tennis betting markets.

These two instruments, CAP curves and AR, are therefore used in the analysis of the predictive power of small bettors, as we are about to describe. The specific proposal is to analyse the predictive power of small bettors in those cases that presented significant differences in the univariate analysis reported above. Thus, we would expect to find small bettors to show greater predictive ability in low-attention events, in early-round matches, in matches not involving any of the so-called "Big Four", in bets placed through means other than a mobile app, in pre-play bets, and in back bets.

The mode of interpretation for the graphs is simple; if the curve is close to the upper lefthand corner, it indicates higher predictive power; while the closer it is to the diagonal, the more random the association. The AR can be derived from the CAP curves by dividing the areas between the CAP curve and the random curve by the area between the ideal CAP curve and the random curve.

The results, which are consistent with those shown in Table 3, enable us to observe that predictive accuracy is greater in low-attention events. In Figure 2, it can be seen that the accuracy is higher for early-round matches than for quarter finals and subsequent rounds, as shown by the accuracy ratios we obtain, of $88.68 \%$ versus $71.08 \%$. The results also shows a greater predictive power for low-attention events, with AR values of $91.41 \%$ versus $74.92 \%$ for those involving one of the big four. 
The predictive accuracy is higher for bets placed prior to the start of the match $(89.10 \%$ versus $79.36 \%$ AR). Figure 2 also shows it to be higher for bets not placed on a mobile app (87.34\% versus $76.53 \%$ AR) and, finally, it reveals higher predictive accuracy for back bets than for lay bets $(85.58 \% \text { versus } 48 \%)^{4}$.

\section{3.- Multivariate Analysis}

The multivariate analysis was performed using various OLS regressions with White's corrected standard errors to control for heteroskedasticity (White, 1980). The first focus of analysis is betting volume. Both the amounts staked and the odds assessment made by our sample bettors may be influenced by behavioural biases or by difficulty in evaluating outcome probabilities. However, the variables used to proxy for these factors could be capturing the same information, thereby generating problems of multicollinearity in the empirical models, as already shown by Abinzano et al. (2019).

The expression used for the analysis takes the following form:

$$
\begin{aligned}
& \log (V O L)_{t}=\alpha+\beta_{1} * \operatorname{LIVE}_{t}+\beta_{2} * S P A_{t}+\beta_{3} * O D D S_{t}+\beta_{4} * A P P_{t}+\beta_{5} * \\
& F A V_{t}+\beta_{6} * A T T_{t}+\varepsilon_{t}
\end{aligned}
$$

where the dependent variable is the log-transformation of betting volume in Euros and the independent variables are those described in the database, with the exception of the variable $A T T$, which stands for event attention and can also be proxied by the dummy variables $Q F, T O P 5$, or $B I G 4^{5}$.

The results of the three model specifications, each using a different variable to measure event attention, are presented in Table 4. The majority of the variables contribute, as expected, to explaining the betting volume generated by small bettors. The initial observation is of a negative relationship between the odds quoted when the bet is placed

\footnotetext{
${ }^{4}$ When analogous CAP and AR analyses were performed for the rest of the variables shown in Table 3, higher AR values were found in matches not involving any of the TOP5, in matches not involving any Spanish players, in bets on favourites, and market order bets (results available upon request).

${ }^{5}$ The joint consideration of the three variables gives rise to multicollinearity problems, as indicated by the condition index values. The presence of multicollinearity issues might suggest that they are capturing the same information, although the QF variable would be more complex in content since it would also be capturing effects due to the increasing closeness in skill levels of the players as the tournament progresses.
} 
$(O D D S)$ and the stake amounts ${ }^{6}$, such that higher odds are associated with lower stakes. This is unsurprising, given that higher odds involve higher risk and higher returns on winning bets.

After accounting for this effect, we find significantly higher stakes in in-play bets, represented by the variable $L I V E$, or bets in the favourite market (FAV). These relationships may be due to the aforementioned possibility of overconfidence in their private information leading small bettors to risk larger amounts.

Lower stakes are found in association with matches involving a Spanish player $(S P A)$, and with one of the three proxies $(Q F)$ used for the degree of attention attracted by the match. These results suggest, in contrast to the above, that, under conditions that increase the likelihood of behavioural biases, bettors reduce the amount they are prepared to risk. Finally, the variable $A P P$ shows no significance in any of the three model specifications, thus suggesting that the stake is in no way influenced by the device used to place the bet. While these findings were not the main purpose of this study, they do nevertheless suggest a relevant relationship between possible behavioural biases in bettors and the volume of betting they generate, consistent with results reported by Abinzano et al. (2019).

After the tests described above, this study addressed its main objective, which was to analyse the possible determining variables of mispricing on the part of small bettors. The equation used for this analysis, which, like the previous one, is estimated using OLS regression and White's corrected standard errors to control for heteroskedasticity (White, 1980), takes the following form:

$$
\begin{aligned}
& M I S_{t}=\alpha+\beta_{1} * L I V E_{t}+\beta_{2} * S P A_{t}+\beta_{3} * L A Y_{t}+\beta_{4} * A P P_{t}+\beta_{5} * \\
& V O L_{t}^{\perp}+\beta_{6} * A T T_{t}+\varepsilon_{t}
\end{aligned}
$$

In this case, the dependent variable, MIS, captures pricing errors and the independent variables are those described in the database section, with the exception of $A T T$, which stands for the degree of attention attracted by the match and is proxied by the same proxies as used previously. The inclusion of betting volume, which probably is proxying for some of the information captured by the rest of the variables, generates multicollinearity problems, as revealed by the condition indices. This was overcome by running auxiliary

\footnotetext{
${ }^{6}$ It is worth recalling that the stakes were converted from lay stakes to back stakes.
} 
regressions between volume and the overlapping variables and using the residual $\left(V O L_{t}^{\perp}\right)$ in the subsequent estimations.

$\log (V O L)_{t}=\alpha+\beta_{1} * \operatorname{LIVE}_{t}+\beta_{2} * E S P_{t}+\beta_{3} * L A Y_{t}+\beta_{4} * A P P_{t}+\beta_{6} *$ $A T T_{t}+\mu_{t}$

where $\mu_{t}=V O L_{t}^{\perp}$.

Once the residuals of regression (6) are entered into estimation of (5), the condition indices show the specified models to be free of multicollinearity.

The results of the estimations described above are given in Table 5, where they can be seen to confirm the findings obtained from the univariate analysis presented previously, in that higher levels of event attention are accompanied by higher levels of mispricing on the part of small bettors. These results hold whether $Q F$ or $B I G 4$ is used to proxy for attention, while also supporting previous evidence linking this type of event with a higher probability of various behavioural biases among bettors (Lahvička, 2014 or Abinzano et al., 2016). This variable yields a non-significant coefficient when proxied by TOP5, however.

All three specifications of the model yield a positive association between the stake and mispricing by small bettors, consistent with the notion that overconfidence in their priors leads small bettors to up their stakes and make errors when assessing the odds. It should be noted, however, that authors such as Abinzano et al. (2019) found the reverse to be the case; that is, higher stakes were associated with lower mispricing. In the context of these studies, the stake amount could be considered a proxy for the level of betting sophistication; given the characteristics of our sample, however, the presence of sophisticated bettors can be considered merely testimonial, as can be inferred from the descriptive statistics shown in Table 2.

The coefficient for the effect of back versus lay betting proves positive and significant in all cases. In other words, higher mispricing is found in relation to lay betting. This amounts to additional evidence to support the findings of Brown and Yang (2018), who show that, in the betting exchange context, the average bettor is unable to identify the best odds. As previously stated, it was expected that the mispricing would be greater among small unsophisticated bettors when using lay odds. 
With respect to device used to place the bet, the coefficient on the $A P P$ variable is positive and significant in all the estimations; that is, higher pricing errors are found to exist in bets placed via a mobile app. This confirms previous findings by Janhuba and Mikulka (2019) showing an association between the means chosen to place the bet and mispricing. It is also consistent with the notion that the magnitude of pricing biases will increase in a context that encourages impulsive or uninformed betting (Hing et al., 2018b).

Finally, the $L I V E$ and $S P A$ variables show no significance in any of the estimations. With respect to the first, despite the univariate analysis having shown higher pricing error for in-play bets, the relationship loses its significance when the rest of the variables are considered. The regression analysis, furthermore, finds no link between mispricing and matches involving a Spanish player.

A last issue to be considered is the possible inter-relationship of APP and LIVE variables. As explained in the database section, the volume of mobile app betting is higher during a match than before it. Bets presenting both these features (APP and LIVE) should therefore have a larger impulsiveness component. This effect is tested by including an interaction term between these two variables in equation (5).

$$
\begin{aligned}
& M I S_{t}=\alpha+\beta_{1} *\left(L_{V} E_{t} * A P P_{t}\right)+\beta_{2} * L I V E_{t}+\beta_{3} * S P A_{t}+\beta_{4} * L A Y_{t} \\
& \beta_{5} * A P P_{t}+\beta_{6} * V O L_{t}^{\perp}+\beta_{7} * A T T_{t}+\varepsilon_{t}
\end{aligned}
$$

The results, presented in Table 6 , show a positive significant interaction effect in all three models. In other words, pricing errors for small bettors are greater in live betting and mobile app betting, in line with the literature on live-action impulsive betting. In addition, the APP variable loses the significance it showed in the previous models. This would appear to suggest that, rather than the device used to place the bet, the key variable is impulsiveness, since it is reasonable to assume that pre-match decision-making is less impulsive. Finally, the only media attention variable to retain significance is QF, which might suggest that the difficulty of predicting the outcome of matches between similar quality players has more influence than the degree of media attention.

In short, our results confirm that, in line with expectations, small bettors' pricing errors depend on a series of variables that could be proxying for factors such as the tournament round, and the bettor's confidence in the final outcome, speed and accuracy in analysing information, and impulsiveness in decision-making. 


\section{6.- Conclusions}

This study takes advantage of the availability of a betting company database mainly made up of small bettors in order to assess their impact on price formation in betting exchanges. The results show that the presence of small bettors generates odds estimation bias potentially leading to permanent mispricing, as predicted by DeLong et al. (1990), or to exploitation by information-seeking, sophisticated bettors, who can bring greater efficiency to the market (Glosten and Milgrom, 1985).

Leaving the market consequences to one side, both models require an instance of mispricing attributable to this type of bettor. This study confirms a link between their presence and inaccurate odds estimates.

Furthermore, the pricing errors made by these bettors are dependent on market conditions or the circumstances in which bets are placed. In line with previous empirical evidence on betting markets, this study finds a higher level of pricing error surrounding highattention events, such as final round matches or those involving top media figures. It is also shown that small bettors are unable to discern between the options offered by betting exchanges, that is, between back betting (for an outcome) and lay betting (against it), given the higher level of pricing error found for lay bets.

Finally, the database has enabled us to check the dependence of pricing errors on the device used to place the bet. This has revealed a higher level of mispricing in ill-informed, impulsive live bets placed via a mobile app.

Although the above results were derived from a betting exchange database, they may still be useful to bookmakers when setting odds or encouraging their customer base to use mobile apps. They may also serve as a guide for regulators and supervisors of the system in their attempts to deter impulsive betting among the users of these devices. 


\section{REFERENCES}

Abinzano, I., Muga, L., Santamaría, R. (2016) "Game, Set and Match: The favouritelongshot bias in tennis betting exchanges", Applied Economics Letters, 23, 605-608.

Abinzano, I., Muga, L., Santamaria, R. (2017) "Behavioral Biases Never Walk Alone: An Empirical Analysis of the Effect of Overconfidence on Probabilities", Journal of Sports Economics, 18, 99 - 125.

Abinzano, I., Muga, L., Santamaria, R. (2019) "Hidden power of trading activity: The FLB in tennis betting exchanges", Journal of Sports Economics, 20, 261 - 285.

Brindley, C. (1999) "The marketing of gambling on the Internet”, Internet Research, 9, 281-286.

Brown, A., Yang, F. (2019) "The wisdom of Large and Small Crowds: Evidence from Repeated Natural Experiments in Sports Betting", International Journal of Forecasting, $35,288-296$.

Brown, A., Yang, F. (2018) "Framing Effects and Market Selection Hypothesis", Available at SSRN: https://ssrn.com/abstract=3087832.

Cantor, R., Mann, C. (2003) "Measuring the Performance of Corporate Bond Ratings". Moody's Special Comment. Available at SSRN: https://ssrn.com/abstract=996025.

Del Corral, J., Prieto-Rodriguez, J. (2010) “Are differences in ranks good predictors for Grand Slam tennis matches?", International Journal of Forecasting, 26, 551-563.

Delong, J., Shleifer, A., Summers, L., Waldmann, R. (1990) "Noise trader risk in financial markets", Journal of Political Economy, 98, 703 - 738.

Fama, E. (1970) "Efficient Capital Markets: A review of Theory and Empirical Work", Journal of Finance, 25, $383-417$.

Flepp, R., Nüesch, S., Franck, E. (2014) "Liquidity, market efficiency and the influence of noise traders: Quasi-experimental evidence from the betting industry", Working paper. Available at SSRN: http://ssrn.com/abstract=2371204.

Flepp, R., Nüesch, S., Franck, E. (2017) "The liquidity advantage of the quote-driven market: Evidence from the betting industry", Quarterly Review of Economics and Finance, 64, 306-317. 
Franck, E.P., Verbeek, E., Nüesch, S. (2010) "Prediction Accuracy of Different Market Structures - Bookmakers Versus a Betting Exchange", International Journal of Forecasting, 26, 448-459.

Franck, E., Verbeek, E., Nüesch, S. (2011). "Sentimental preferences and the organizational regime of betting markets", Southern Economic Journal, 78, 502-518.

Frazzini, A. (2006) "The disposition effect and under-reaction to news", Journal of Finance, 61, 2017 - 2046.

Fuentes, C., Svingstedt, A. (2017) "Mobile Phones and the Practice of Shopping: A Study of How Young Adults Use Smartphones to Shop", Journal of Retailing and Consumer Services, 36, $137-146$.

Gandhi, A., Serrano-Padial, R. (2015) "Does belief heterogeneity explain asset prices?: The case of Longshot bias", Review of Economic Studies, 82, 156-186.

Gharghori, P, Chan, H., Faff, R. (2006) "Investigating the performance of alternative default-risk models: Option-based versus accounting-based approaches", Australian Journal of Management, 31, 2, 207 - 234.

Glosten, L. R., Milgrom, P. R. (1985) "Bid, Ask, and Transaction Prices in a Specialist Marketwith Heterogenously Informed Traders", Journal of Financial Economics, 14, 1, 71-100.

Grob, M. (2015a) "Exploring the acceptance of technology for mobile shopping: An Empirical Investigation among Smartphone Users", The International Review of Retail Distribution Consumer Research, 25, 215 - 235.

Grob, M. (2015b) "Mobile Shopping: A Classification Framework and Literature Review”, International Journal of Retail and Distribution Management, 43, 221 - 241.

Hing, N., Li, E., Vitartas, P., Russell, A.M.T. (2018a) "On the spur of the moment: Intrinsic predictors of impulse sports betting”, Journal of Gambling Studies, 34, 413-428.

Hing, N., Russell, A.M.T., Li, E., Vitartas, P. (2018b) "Does the uptake of wagering inducements predict impulse betting on sport?", Journal of Behavioral Addictions, 7, 1, 146-157. 
Hurley, W., McDonough, L. (1995) “A note on the Hayek Hypothesis and the favouritelongshot bias in pari-mutuel betting”, American Economic Review, 85, 949 - 955.

James, C., Karceski, J. (2006) "Investor monitoring and differences in mutual fund performance", Journal of Banking and Finance, 30, 2787 - 2808.

James, R.J.E, O’Malley, C., Tunney, R.J. (2017) "Understanding the psychology of mobile gambling: A behavioural synthesis", British Journal of Psychology, 108, 608-625. Janhuba, R., Mikulka, J. (2019) "High Bets for the Win? The Role of Stake Size in Sports Betting”, CERGE Working Paper.

Jones, P., Hillier, D., Turner, D., Comfort, D. (2004) "Betting on the exchanges: changing customer relationships in the sports betting market in the UK", Management Research News, 27, 95-103.

Kealhofer, S. (2003) “Quantifying Credit Risk I: Default Prediction”, Financial Analysts Journal, 59, 1, $30-44$.

Kock, A.K., Shing, H.F. (2008) "Bookmaker and pari-mutuel betting: Is a (reverse) favourite-longshot bias built-in?", The Journal of Prediction Markets, 2, 29-52.

Kumar, A. (2009) "Hard-to-Value Stocks, Behavioral Biases, and Informed Trading", Journal of Financial and Quantitative Analysis, 44, 1375-1401.

Kuypers, T. (2000) "Information and efficiency: An empirical study of a fixed odds betting market", Applied Economics, 32, 1353-1363.

Lahvička, J. (2014) "What causes the favourite-longshot bias? Further evidence from tennis", Applied Economic Letters, 21, 90-92.

Lyócsa, S., Fedorko, I. (2016) "What drives intermediation costs? A case of tennis betting market”, Applied Economics, 48, 2037 - 2053.

Lyócsa, S., Výros, T. (2018) "To bet or not to bet: A reality check for tennis betting market efficiency", Applied Economics, 50, 2251 - 2272.

Makropoulou, V., Markellos R.N. (2011) "Optimal price setting in fixed-odds betting markets under information uncertainty", Scottish Journal of Political Economy, 58, 519 $-536$. 
Parke, A., Harris, A., Parke, J., Rigbye, J., Blaszczynski, A. (2014). "Responsible marketing andadvertising in gambling: A critical review", The Journal of Gambling Business and Economics, 8, 21-35.

Rossi, M. (2011) "Match rigging and the favorite longshot bias in the Italian Football betting market", International Journal of Sport Finance, 6, 317 - 334.

Shankar, V., Balasubramanian, S. (2009) "Mobile Marketing: A Synthesis and Prognosis", Journal of Interactive Marketing, 23, 118 - 129.

Sobehart, J., Keenan, S., Stein, R. (2001) "Benchmarking Quantitative Default Risk Models: A Validation Methodology", Algo Research Quarterly, 4, 1-2, 57-72.

Sohn, S. (2017) “A Contextual Perspective on Consumers' Perceived Usefulness: The Case of Mobile Online Shopping”, Journal of Retail and Consumer Services, 38, 22-33.

White, H. (1980) “A Heteroskedasticity-Consistent Covariance Matrix Estimator and a Direct Test for Heteroskedasticity", Econometrica, 48, 817-838.

Vaughan-Williams, L. (1999) "Information Efficiency in Betting Markets: A Survey", Bulletin of Economic Research, 51, 1 - 39. 
TABLE 1: DESCRIPTIVE STATISTICS: BETS AND MATCHES

\begin{tabular}{ccccccc}
\hline \multicolumn{7}{l}{ PANEL A: FAVOURITE MARKET } \\
\hline ROUND & MATCHES & TOTAL & PE & IP & BACK & LAY \\
\hline R1 & 31 & $15.16 \%$ & $57.97 \%$ & $42.03 \%$ & $89.86 \%$ & $10.14 \%$ \\
R2 & 21 & $17.80 \%$ & $28.40 \%$ & $71.60 \%$ & $96.30 \%$ & $3.70 \%$ \\
R3 & 11 & $12.97 \%$ & $61.02 \%$ & $38.98 \%$ & $100.00 \%$ & $0.00 \%$ \\
R4 & 8 & $15.16 \%$ & $42.03 \%$ & $57.97 \%$ & $95.65 \%$ & $4.35 \%$ \\
QF & 4 & $9.23 \%$ & $83.33 \%$ & $16.67 \%$ & $88.10 \%$ & $11.90 \%$ \\
SF & 2 & $20.00 \%$ & $30.77 \%$ & $69.23 \%$ & $90.11 \%$ & $9.89 \%$ \\
F & 1 & $9.67 \%$ & $50.00 \%$ & $50.00 \%$ & $93.18 \%$ & $6.82 \%$ \\
TOTAL & 78 & $100.00 \%$ & $46.81 \%$ & $53.19 \%$ & $95.38 \%$ & $6.59 \%$ \\
\hline PANEL B: LONGSHOT MARKET & & & & \\
\hline ROUND & MATCHES & TOTAL & PE & $\mathbf{I P}$ & $\mathbf{B A C K}$ & LAY \\
\hline R1 & 23 & $12.75 \%$ & $44.74 \%$ & $55.26 \%$ & $73.68 \%$ & $26.32 \%$ \\
R2 & 13 & $9.73 \%$ & $62.07 \%$ & $37.93 \%$ & $79.31 \%$ & $20.69 \%$ \\
R3 & 11 & $11.74 \%$ & $62.86 \%$ & $37.14 \%$ & $88.57 \%$ & $11.43 \%$ \\
R4 & 7 & $25.17 \%$ & $50.67 \%$ & $49.33 \%$ & $94.67 \%$ & $5.33 \%$ \\
QF & 4 & $10.07 \%$ & $80.00 \%$ & $20.00 \%$ & $93.33 \%$ & $6.67 \%$ \\
SF & 2 & $18.12 \%$ & $48.15 \%$ & $51.85 \%$ & $79.63 \%$ & $20.37 \%$ \\
F & 1 & $12.42 \%$ & $16.22 \%$ & $83.78 \%$ & $78.38 \%$ & $21.62 \%$ \\
TOTAL & 61 & $100.00 \%$ & $50.67 \%$ & $49.33 \%$ & $84.90 \%$ & $15.10 \%$ \\
\hline TOTAL & & $\mathbf{7 5 3}$ & $\mathbf{3 6 4}$ & $\mathbf{3 8 6}$ & $\mathbf{6 8 7} \%$ & $\mathbf{7 5}$ \\
\hline
\end{tabular}

This table shows the percentages of in-play (IP) bets versus pre-event (PE) bets, and back bets (BACK) versus lay bets (LAY) by market type (FAVOURITE MARKET, panel A; LONGSHOT $M A R K E T$, panel $B$ ) and round of the tournament. 
TABLE 2: DESCRIPTIVE STATISTICS

\begin{tabular}{ccccccc}
\hline & Mean & Median & Maximum & Minimum & Std. Dev. & Skewness \\
\hline BIG4 & 0.539 & 1 & 1 & 0 & 0.499 & -0.157 \\
QF & 0.396 & 0 & 1 & 0 & 0.489 & 0.426 \\
TOP 5 & 0.319 & 0 & 1 & 0 & 0.466 & 0.778 \\
LIVE & 0.517 & 1 & 1 & 0 & 0.501 & -0.066 \\
SPA & 0.396 & 0 & 1 & 0 & 0.489 & 0.426 \\
FAV & 0.604 & 1 & 1 & 0 & 0.489 & -0.426 \\
VOL & 113.81 & 20 & 18759 & 0.05 & 778.21 & 19.44 \\
ODDS & 2.675 & 1.758 & 26.641 & 1.001 & 2.720 & 3.758 \\
TIME & 0.256 & 0 & 1 & 0 & 0.437 & 1.116 \\
MIS & 0.022 & -0.049 & 0.989 & -0.949 & 0.461 & 0.086 \\
APP & 0.298 & 0 & 1 & 0 & 0.458 & 0.881 \\
LAY & 0.099 & 0 & 1 & 0 & 0.299 & 2.674 \\
\hline
\end{tabular}

This table shows the basic descriptive statistics for the main variables used in this study. BIG4 takes the value 1 if the match involves one of the four top media figures; $Q F$, which takes the value 1 if it is a quarter-, semi- or final match; TOP5, takes the value 1 if the match involves one of the 5 players highest-seeded at the start of the tournament; LIVE is a dummy variable for "in play" bets; SPA is a dummy variable which takes the value 1 for bets placed on matches where at least one of the players is Spanish; FAV is a dummy variable that takes a value of 1 for bets placed in the favourite market; VOL stands for the amount staked; ODDS is the quote for the bet; TIME is a dummy variable which takes a value of 1 if the bet entered the market as a limited order; MIS is the variable that proxies mispricing; APP is a variable that takes a value of 1 if the bet was placed from a mobile app and, finally $L A Y$ is a dummy variable for lay bets. 
TABLE 3: UNIVARIATE ANALYSIS

\begin{tabular}{|c|c|c|c|c|c|c|c|c|c|}
\hline \multicolumn{10}{|c|}{ PANEL A: DETERMINANTS OF THE STAKE } \\
\hline VOL & BIG 4 & QF & TOP 5 & LIVE & SPA & FAV & TIME & APP & LAY \\
\hline 1 & 69.628 & 36.213 & 99.919 & 126.380 & 45.345 & 170.235 & 77.536 & 57.763 & 273.532 \\
\hline $\mathbf{0}$ & 165.498 & 164.627 & 120.305 & 100.360 & 158.646 & 27.65 & 126.307 & 137.689 & 96.139 \\
\hline dif & -98.869 & $-128.413 * *$ & -20.386 & 26.020 & $-113.30 * *$ & $142.58 * *$ & -48.771 & $-79.925 *$ & 177.393 \\
\hline t-stat & -1.581 & 4.807 & -0.335 & 0.467 & -2.412 & 3.045 & -1.188 & -1.953 & 0.709 \\
\hline \multicolumn{10}{|c|}{ PANEL B: DETERMINANTS OF MISPRICING } \\
\hline MIS & BIG 4 & QF & TOP 5 & LIVE & SPA & FAV & TIME & APP & LAY \\
\hline 1 & 0.068 & 0.123 & 0.022 & 0.062 & 0.041 & 0.0195 & 0.054 & 0.172 & 0.201 \\
\hline $\mathbf{0}$ & -0.033 & -0.045 & 0.021 & -0.022 & 0.008 & 0.0245 & 0.01 & -0.0427 & 0.002 \\
\hline dif & $0.102 * *$ & $0.168^{* *}$ & 0.001 & $0.084^{* *}$ & 0.033 & -0.005 & 0.044 & $0.214^{* *}$ & $0.199 * *$ \\
\hline t-stat & 3.112 & 4.807 & 0.036 & 2.529 & 0.971 & -0.145 & 1.154 & 5.772 & 3.141 \\
\hline
\end{tabular}

Panel A presents the differences in average stakes for each of the variables considered in this study, together with their t-statistics. Panel B presents the differences in average values of the MIS variable for each of the variables considered in this study, together with their t-statistics. ** denotes difference significant at 5\% level and * denotes difference significant at 10\% level. BIG4 takes the value 1 if the match involves one of the four top media figures; QF, which takes the value 1 if it is a quarter-, semi- or final match; TOP5, takes the value 1 if the match involves one of the 5 players highest-seeded at the start of the tournament; LIVE is a dummy variable for "in play" bets; SPA is a dummy variable which takes the value 1 for bets placed on matches where at least one of the players is Spanish; FAV is a dummy variable that takes a value of 1 for bets placed in the favourite market; TIME is a dummy variable which takes a value of 1 if the bet entered the market as a limited order; APP is a variable that takes a value of 1 if the bet was placed from a mobile app and, finally, LAY is a dummy variable for lay bets. 
TABLE 4: MULTIVARIATE ANALYSIS: Volume

\begin{tabular}{|c|c|c|c|c|c|c|}
\hline VARIABLE & MODEL 1 & & MODEL 2 & & MODEL 3 & \\
\hline LIVE & $\begin{array}{r}0.593725 \\
(0.000)\end{array}$ & $* *$ & $\begin{array}{r}0.598661 \\
(0.000)\end{array}$ & $* *$ & $\begin{array}{r}0.615922 \\
(0.000)\end{array}$ & $* *$ \\
\hline SPA & $\begin{array}{r}-0.305273 \\
(0.008)\end{array}$ & $* *$ & $\begin{array}{r}-0.376768 \\
(0.001)\end{array}$ & $* *$ & $\begin{array}{r}-0.339749 \\
(0.005)\end{array}$ & $* *$ \\
\hline ODDS & $\begin{array}{r}-0.195169 \\
(0.000)\end{array}$ & $* *$ & $\begin{array}{r}-0.189211 \\
(0.000)\end{array}$ & $* *$ & $\begin{array}{r}-0.188624 \\
(0.000)\end{array}$ & $* *$ \\
\hline APP & $\begin{array}{r}-0.102598 \\
(0.3831)\end{array}$ & & $\begin{array}{r}-0.133909 \\
(0.255)\end{array}$ & & $\begin{array}{r}-0.117948 \\
(0.320)\end{array}$ & \\
\hline FAV & $\begin{array}{r}0.512129 \\
(0.000)\end{array}$ & $* *$ & $\begin{array}{r}0.535292 \\
(0.000)\end{array}$ & $* *$ & $\begin{array}{r}0.535056 \\
(0.000)\end{array}$ & $* *$ \\
\hline QF & $\begin{array}{r}-0.226041 \\
(0.052)\end{array}$ & $*$ & & & & \\
\hline TOP 5 & & & $\begin{array}{r}0.013850 \\
(0.911)\end{array}$ & & & \\
\hline BIG 4 & & & & & $\begin{array}{r}-0.102160 \\
(0.428)\end{array}$ & \\
\hline C & $\begin{array}{r}3.052 \\
(0.000)\end{array}$ & $* *$ & $\begin{array}{r}2.963 \\
(0.000)\end{array}$ & $* *$ & $\begin{array}{r}2.993 \\
(0.000)\end{array}$ & $* *$ \\
\hline ADJ R2 & 0.201 & & 0.197 & & 0.198 & \\
\hline
\end{tabular}

Test Results from Model (4) for the Various ATT variable considered obtained via OLS with White (1980) Standard Errors. ** denotes difference significant at 5\% level and * denotes difference significant at 10\% level. BIG4 takes the value 1 if the match involves one of the four top media figures; $Q F$, which takes the value 1 if it is a quarter-, semi-or final match; TOP5, takes the value 1 if the match involves one of the 5 players highest-seeded at the start of the tournament; LIVE is a dummy variable for "in play" bets; SPA is a dummy variable which takes the value 1 for bets placed on matches where at least one of the players is Spanish; ODDS is the quote for the bet; FAV is a dummy variable that takes a value of 1 for bets placed in the favourite market; APP is a variable that takes a value of 1 if the bet was placed from a mobile app and, finally, LAY is a dummy variable for lay bets. 
TABLE 5: MULTIVARIATE ANALYSIS: Mispricing

\begin{tabular}{|c|c|c|c|c|c|c|}
\hline VARIABLE & MODEL 1 & & MODEL 2 & & MODEL 3 & \\
\hline \multirow[t]{2}{*}{ LIVE } & 0.041405 & & 0.035231 & & 0.025542 & \\
\hline & $(0.212)$ & & $(0.289)$ & & $(0.446)$ & \\
\hline \multirow[t]{2}{*}{ SPA } & -0.039887 & & 0.008382 & & -0.015389 & \\
\hline & $(0.245)$ & & $(0.799)$ & & $(0.681)$ & \\
\hline \multirow[t]{2}{*}{ LAY } & 0.200502 & $* *$ & 0.216447 & $* *$ & 0.214549 & $* *$ \\
\hline & $(0.001)$ & & $(0.000)$ & & $(0.000)$ & \\
\hline \multirow[t]{2}{*}{ APP } & 0.194948 & $* *$ & 0.217331 & $* *$ & 0.208371 & $* *$ \\
\hline & $(0.000)$ & & $(0.000)$ & & $(0.000)$ & \\
\hline \multirow[t]{2}{*}{ VOL } & 0.055126 & $* *$ & 0.054182 & $* *$ & 0.054933 & $* *$ \\
\hline & $(0.000)$ & & $(0.000)$ & & $(0.000)$ & \\
\hline \multirow[t]{2}{*}{ QF } & 0.144329 & $* *$ & & & & \\
\hline & $(0.000)$ & & & & & \\
\hline \multirow[t]{2}{*}{ TOP-5 } & & & 0.000061 & & & \\
\hline & & & (0.998) & & & \\
\hline \multirow[t]{2}{*}{ BIG 4} & & & & & 0.060214 & $*$ \\
\hline & & & & & $(0.098)$ & \\
\hline \multirow[t]{2}{*}{ C } & -0.119424 & $* *$ & -0.086514 & $* *$ & -0.101681 & $* *$ \\
\hline & $(0.000)$ & & $(0.002)$ & & $(0.000)$ & \\
\hline ADJ R2 & 0.118 & & 0.097 & & 0.101 & \\
\hline
\end{tabular}

Test Results from Model (5) for the Various ATT variable considered Obtained via OLS with White (1980) Standard Errors. ** denotes difference significant at 5\% level and * denotes difference significant at 10\% level. BIG4 takes the value 1 if the match involves one of the four top media figures; $Q F$, which takes the value 1 if it is a quarter-, semi- or final match; TOP5, takes the value 1 if the match involves one of the 5 players highest-seeded at the start of the tournament; LIVE is a dummy variable for "in play" bets; SPA is a dummy variable which takes the value 1 for bets placed on matches where at least one of the players is Spanish; APP is a variable that takes a value of 1 if the bet was placed from a mobile app LAY is a dummy variable for lay bets and, finally, VOL represents the residual effect of the stake. 
TABLE 6: MULTIVARIATE ANALYSIS: Interaction Effect Live-App

\begin{tabular}{|c|c|c|c|c|c|c|}
\hline VARIABLE & MODEL 1 & & MODEL 2 & & MODEL 3 & \\
\hline LIVE*APP & $\begin{array}{r}0.266841 \\
(0.001)\end{array}$ & $* *$ & $\begin{array}{r}0.312985 \\
(0.000)\end{array}$ & $* *$ & $\begin{array}{r}0.302966 \\
(0.000)\end{array}$ & $* *$ \\
\hline LIVE & $\begin{array}{r}-0.033608 \\
(0.371)\end{array}$ & & $\begin{array}{r}-0.050641 \\
(0.176)\end{array}$ & & $\begin{array}{r}-0.056703 \\
(0.131)\end{array}$ & \\
\hline SPA & $\begin{array}{r}-0.038154 \\
(0.261)\end{array}$ & & $\begin{array}{r}-0-002545 \\
(0.939)\end{array}$ & & $\begin{array}{r}-0.017027 \\
(0.643)\end{array}$ & \\
\hline LAY & $\begin{array}{r}0.204038 \\
(0.001)\end{array}$ & $* *$ & $\begin{array}{r}0.217183 \\
(0.000)\end{array}$ & $* *$ & $\begin{array}{r}0.216221 \\
(0.000)\end{array}$ & $* *$ \\
\hline APP & $\begin{array}{r}0.038129 \\
(0.516)\end{array}$ & & $\begin{array}{r}0.030128 \\
(0.598)\end{array}$ & & $\begin{array}{r}0.028251 \\
(0.625)\end{array}$ & \\
\hline VOL & $\begin{array}{r}0.050539 \\
(0.000)\end{array}$ & $* *$ & $\begin{array}{r}0.049857 \\
(0.000)\end{array}$ & $* *$ & $\begin{array}{r}0.049851 \\
(0.000)\end{array}$ & $* *$ \\
\hline QF & $\begin{array}{r}0.122725 \\
(0.001)\end{array}$ & $* *$ & & & & \\
\hline TOP-5 & & & $\begin{array}{r}-0.017500 \\
(0.609)\end{array}$ & & & \\
\hline BIG 4 & & & & & $\begin{array}{r}0.048567 \\
(0.184)\end{array}$ & \\
\hline C & $\begin{array}{r}-0.078749 \\
(0.006)\end{array}$ & $* *$ & $\begin{array}{r}-0.037883 \\
(0.198)\end{array}$ & & $\begin{array}{r}-0.058158 \\
(0.039)\end{array}$ & $* *$ \\
\hline ADJ R2 & 0.141 & & 0.127 & & 0.129 & \\
\hline
\end{tabular}

Test Results from Model (7) for the Various ATT variable considered Obtained via OLS with White (1980) Standard Errors. ${ }^{* *}$ denotes difference significant at 5\% level and * denotes difference significant at 10\% level. BIG4 takes the value 1 if the match involves one of the four top media figures; QF, which takes the value 1 if it is a quarter-, semi- or final match; TOP5, takes the value 1 if the match involves one of the 5 players highest-seeded at the start of the tournament; LIVE is a dummy variable for "in play" bets; SPA is a dummy variable which takes the value 1 for bets placed on matches where at least one of the players is Spanish; APP is a variable that takes a value of 1 if the bet was placed from a mobile app LAY is a dummy variable for lay bets and, finally, VOL represents the residual effect of the stake. 
FIGURE 1: MATCH ODDS AUSTRALIAN OPEN FINAL 2017

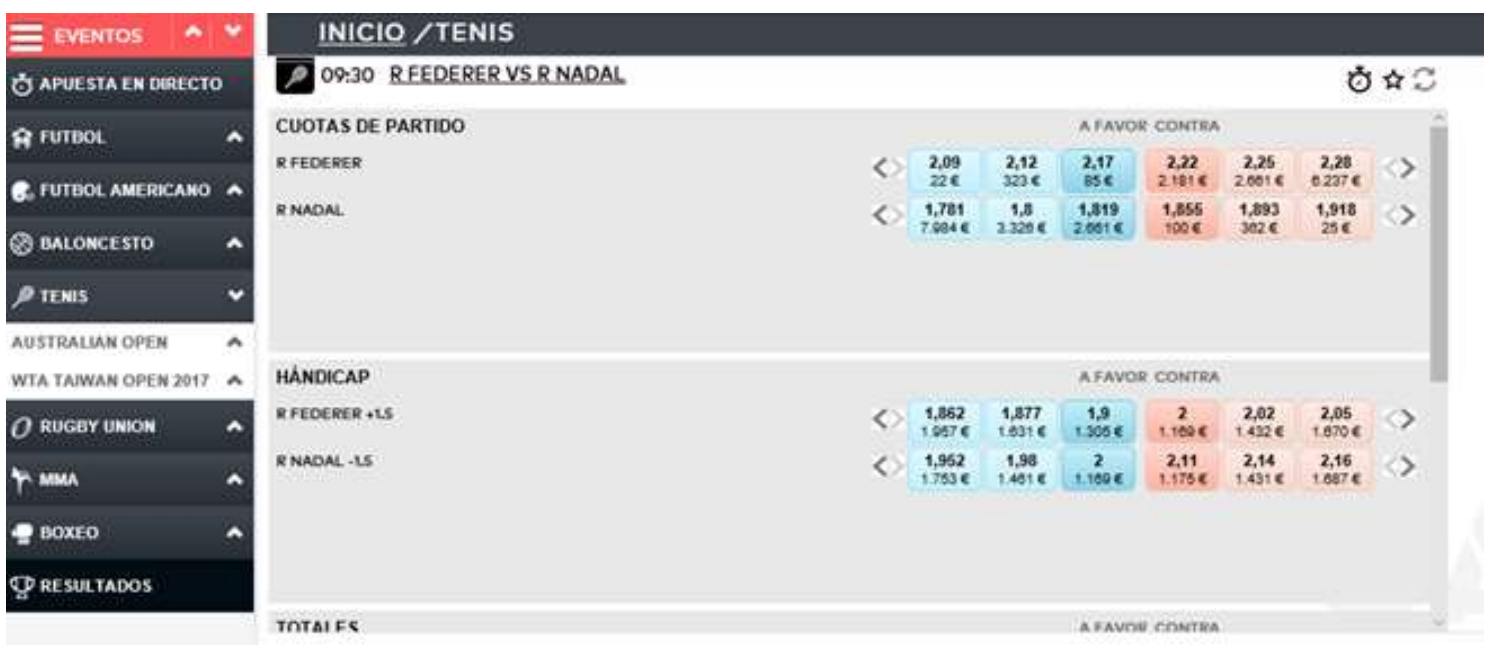




\section{FIGURE 2: CAP CURVES REGARDING DIFFERENT CHARACTERISTICS}
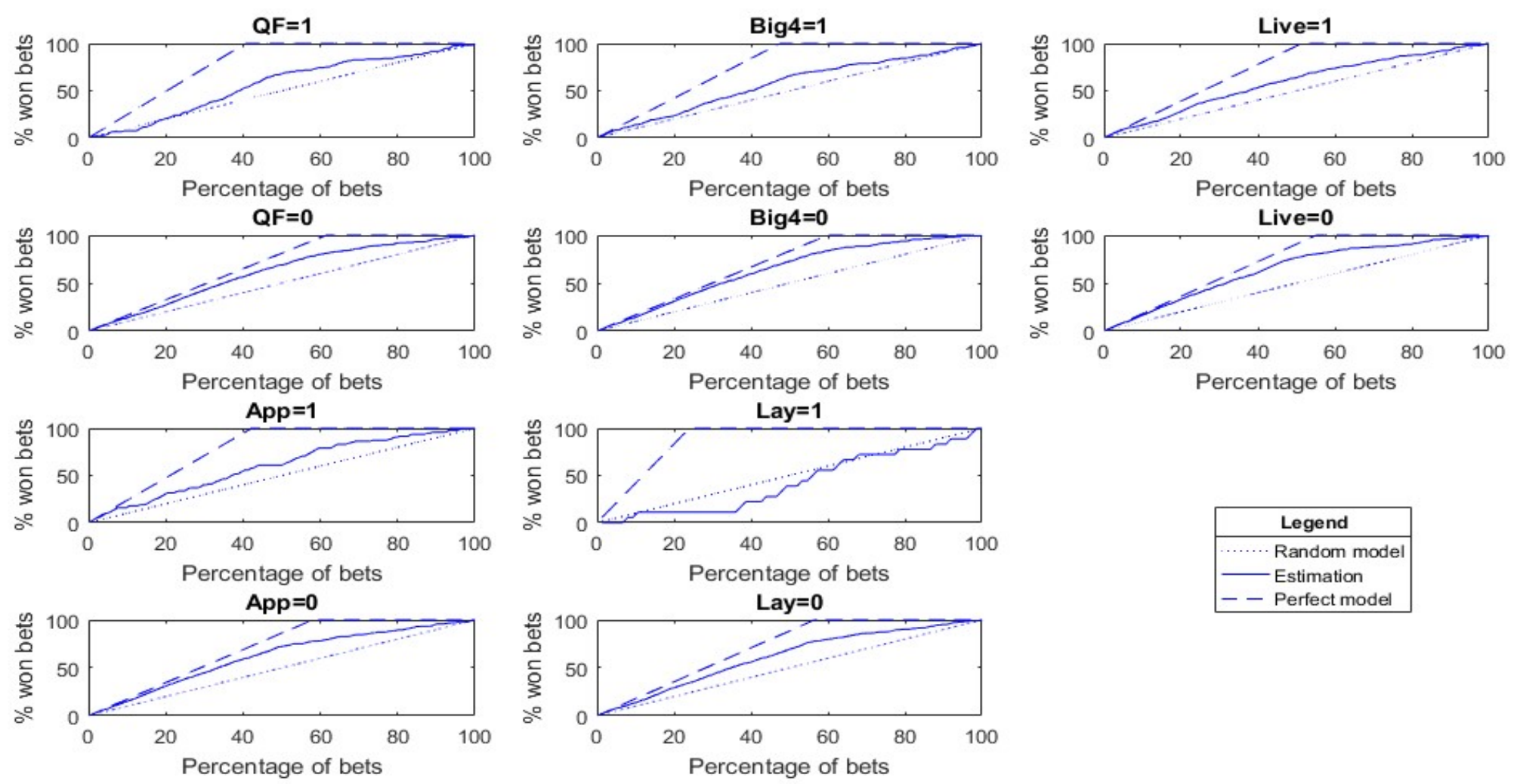

The continuous line (estimation) represents the percentage of winning bets in relation to the percentage of total bets ordered according to their winning probability. The dashed line (perfect model) represents what should occur, that is, the percentage of winning bets based on higher winning probability. Finally, the dotted line (random model) represents the random model, according to which the percentage of winners is equal to that of the sample. BIG4 takes the value 1 if the match involves one of the four top media figures; QF, which takes the value 1 if it is a quarter-, semi- or final match; LIVE is a dummy variable for "in play" bets; APP is a variable that takes a value of 1 if the bet was placed from a mobile app and, finally, LAY is a dummy variable for lay bets. 